\title{
Analysis of variants at LGALS3 single nucleotide polymorphism loci in skull base chordoma
}

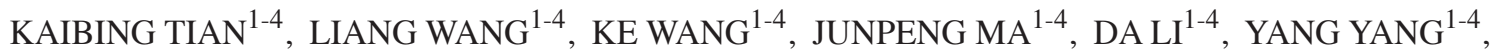 \\ GUIJUN JIA ${ }^{1-4}$, ZHEN WU ${ }^{1-4}$, LIWEI ZHANG ${ }^{1-4}$ and JUNTING ZHANG ${ }^{1-4}$ \\ ${ }^{1}$ Department of Neurosurgery, Beijing Tiantan Hospital, Capital Medical University; ${ }^{2}$ Center of Brain Tumor, \\ China National Clinical Research Center for Neurological Diseases; ${ }^{3}$ Center of Brain Tumor, Beijing \\ Institute for Brain Disorders; ${ }^{4}$ Beijing Key Laboratory of Brain Tumor, Beijing 100050, P.R. China
}

Received April 27, 2016; Accepted April 9, 2018

DOI: $10.3892 / 01.2018 .8780$

\begin{abstract}
Although LGALS3 has been widely studied, the genotypes of the LGALS3 single nucleotide polymorphism (SNP) loci in skull base chordoma (SBC) have been not well defined. The aim of the current study was to analyze two LGALS3 SNP genotypes in patients with SBC. A total of 48 patients with SBC who underwent surgical treatment in Department of Neurosurgery, Beijing Tiantan Hospital, Capital Medical University (Beijing, China) and 66 healthy participants were included in the present study. A total of two SNPs (LGALS3+191 C >A and LGALS3 +292 A >C) were selected for sequencing analysis of amplified target fragments from DNA that was extracted from blood samples. The clinical features of the patients were recorded, follow-up was conducted and statistical analysis was performed with SPSS 20.0. There were no differences in age and sex between the patients and control group. In addition, there were no significant differences in the distribution of genotypes $(\mathrm{P}=0.662)$ and allelic frequencies $(\mathrm{P}=0.638)$ at LGALS3 $+191 \mathrm{C}>\mathrm{A}$ between the two groups. However, significant difference was observed in the allelic distributions at LGALS $3+292 \mathrm{~A}>\mathrm{C}$ between them $(\mathrm{P}=0.016)$, and allele $\mathrm{A}$ was associated with the occurrence of SBC. The distribution of the genotypes at LGALS3 $+292 \mathrm{~A}>\mathrm{C}$ was not significantly different in the additive model (CC vs. AC vs. AA, $\mathrm{P}=0.083$ ) but was significantly different in the dominant model $(\mathrm{CC}+\mathrm{AC}$ vs. AA, $\mathrm{P}=0.043)$. In the Kaplan-Meier
\end{abstract}

Correspondence to: Dr Junting Zhang or Dr Zhen Wu, Department of Neurosurgery, Beijing Tiantan Hospital, Capital Medical University, Tiantan Xili 6, Dongcheng, Beijing 100050, P.R. China E-mail: zhangjun ting2003@aliyun.com

E-mail: wuzhen1966@aliyun.com

Abbreviations: SNP, single nucleotide polymorphism; SBC, skull base chordoma; K-M, Kaplan-Meier; MR, magnetic resonance; NTR, near total resection; PR, partial resection; STR, subtotal resection

Key words: galectin-3, gene, skull base, chordoma analysis, there were no significant differences in the overall survival and progression analysis between different genotypes at LGALS3 $+191 \mathrm{C}>\mathrm{A}(\mathrm{P}=0.168$ and $\mathrm{P}=0.120)$ in patients with SBC. There was no significant difference in overall survival was observed between the genotypes at $+292 \mathrm{~A}>\mathrm{C}(\mathrm{P}=0.595)$. However, the progression-free survival (PFS) time of the $\mathrm{CC}+\mathrm{AC}$ genotype group was longer compared with the AA genotype group $(\mathrm{P}<0.001)$. In the univariate and multivariate analysis of tumor progression, PFS was shorter in the AA genotype group compared with the $\mathrm{CC}+\mathrm{AC}$ genotype group $(\mathrm{P}<0.001)$. The allele A and AA genotype at LGALS3 +292 $\mathrm{A}>\mathrm{C}$ were observed to be associated with a higher risk of SBC, and the AA genotype at $+292 \mathrm{~A}>\mathrm{C}$ was associated with a shorter PFS time.

\section{Introduction}

Chordoma is a rare malignant tumor derived from residual embryonic notochord tissue with an incidence rate of $\sim 0.08$ to 0.089 per 100,000 people (1-5). Chordoma primarily occurs in the axial skeleton, of which $32-42 \%$ is located in the base of the skull $(1,3,6)$. The biological behaviors of the majority of chordomas exhibit low-degree malignancy, and chordomas are insensitivite to chemotherapy (7-9). To date, complete surgical removal and postoperative radiotherapy remain the main treatment option (10-12). However, skull base chordoma (SBC) causes bone destruction and invasion in its growth. In addition, SBC tumors often surround important blood vessels and cranial nerves at the base of the skull; these factors may lead to incomplete resection of the tumor in numerous patients. Long-term follow-up shows a poor prognosis with a high relapse rate $(88.3 \%$ at 10 years) and low long-term survival rate (only $59.5 \%$ at 10 years) (13).

Galectin-3 is a protein with a molecular weight of 29 to $35 \mathrm{kDa}$ (14-17), which was named according to the nomenclature that was published in 1994 (18). Galectin-3 is encoded by the LGALS3 gene, which is located on chromosome 14 [locus q21-q22], and is composed of 6 exons and five introns $(19,20)$. Galectin-3 is widely distributed in various human tissues and has multiple roles in a variety of biological processes by interacting with intracellular and extracellular proteins. Galectin-3 functions under many physiological and pathophysiological 
conditions and is involved in cell growth, differentiation, immune response, tumor metastasis and apoptosis $(21,22)$. Galectin-3 has been reported in a variety of neoplasms, including thyroid carcinoma, carcinoma of the prostate, ovarian cancer, breast carcinoma, lung cancer, colon cancer, glioma and chordoma (23-28).

Several reports confirmed the expression of galectin-3 in chordoma (28-31), and its expression level is higher in chordoma compared with normal spinal cord tissue (28). In addition, it has been reported that galectin-3 can be used as a reliable immunohistochemical marker to identify chordoma and low-grade chondrosarcoma (another bone neoplasm) (30).

According to the literature, there are two single nucleotide polymorphism (SNP) loci of galectin-3 (rs4644 and rs4652) (32-34). In the galectin-3 variant carrying SNP rs4644, LGALS3 +191 C>A, the histidine residue at the position 64 of LGALS3 is replaced by a proline residue. Meanwhile, in the variant carrying SNP rs4652, namely LGALS3 +292 A >C, the threonine residue at the position 98 of LGALS3 is replaced by a proline residue (32-34)

The hypothesis of the present study was that the genotypes of the two SNPs could be useful for studying SBC. Therefore, the aim of the present study was to investigate the usefulness of the two SNPs genotypes in predicting the occurrence of SBC and to evaluate the usefulness of the two SNPs genotypes as a variable in studying SBC.

\section{Materials and methods}

Subjects. In the present study, patients with SBC and who underwent surgical therapy between 1 January 2005 and 31 December 2014 at the Skull Base Ward of Beijing Tiantan Hospital, Capital Medical University (Beijing, China) were recruited, and 199 patients with SBC underwent surgical treatment during this period. Blood samples were obtained from 89 patients. A total of 36 patients underwent preoperative chemotherapy or radiotherapy, 3 patients had other malignant tumor types (thyroid carcinoma in 1 patient, mammary cancer in 1 patient and uterine cancer in 1 patient) during the follow-up, and the clinical records of 2 patients were not available in the remaining 50 patients. Therefore, 48 patients were enrolled in the patient group. Additionally, 66 sex- and age-matched healthy participants were incorporated in the control group. All of the 48 patients (median $40 \pm 12.784$ years) were pathologically confirmed as chordoma patients. In addition, 66 healthy controls were selected (median $40.5 \pm 10.259$ years); all of the subjects were unrelated, healthy Chinese people. The subject exclusion criteria included: i) Subjects with nervous system diseases and a history of tumors other than SBC; ii) patients with chemotherapy or radiotherapy history and iii) patients without available medical records and preoperative magnetic resonance (MR) images. The present study is in accordance with the Code of Ethics of the World Medical Association (Declaration of Helsinki) for experiments involving humans and was approved by the ethics committees of Beijing Tiantan Hospital (Beijing, China) and the Capital Medical University (Beijing, China). All subjects signed informed consent forms prior to the start of the experiments.

The patients aged from 11 to 62 years (median $40 \pm 12.784$ years), and the healthy participants aged from
25 to 79 years (median $40.5 \pm 10.259$ years). There were no differences in age between the two groups $(\mathrm{P}=0.118)$. The ratio of female to male was 1:1 in patients with SBC and 31:35 in normal controls. There was no difference in terms of sex in the two groups $(\mathrm{P}=0.850)$.

Genetic typing of LGALS3 SNPs. Peripheral blood samples $(5 \mu \mathrm{l})$ were extracted from each subject. DNA was extracted from blood leukocytes with the blood DNA extraction kit (DP318; TIANamp Blood DNA kit; Tiangen Biotech Co., Ltd., Beijing, China). The extracted DNA samples were stored at $-20^{\circ} \mathrm{C}$ until use. As rs4644 and rs4652 are located in the exon 3 of LGALS3, one pair of primers was used for PCR (polymerase chain reaction) amplification. The primers were designed as follows: Forward: 5'-TGATGCGTTATCTGGGTC TG-3', and reverse: 5'-AGAAGGAATGCCATCTCACC-3'. The target fragment was amplified in a $50 \mu \mathrm{l}$ PCR reaction for 35 cycles consisting of $94^{\circ} \mathrm{C}$ for $30 \mathrm{sec}, 57^{\circ} \mathrm{C}$ for $35 \mathrm{sec}$, and $72^{\circ} \mathrm{C}$ for $40 \mathrm{sec}$. Genotyping by sequencing was performed by Sangon Biotech Co., Ltd., (Shanghai, China).

Clinical analysis. The clinical data of the patients were acquired from inpatient records. Follow-up was conducted mainly in an outpatient setting; telephone interviews were used for 3 patients who were unable to visit the hospital. Tumor progression was defined as the recurrence or regrowth of the residual tumor.

The clinical data of the patients were recorded in detail. The treatment history was recorded as either with or without treatment history and with treatment history. Details of the operation and the characteristics of SBC were acquired from the operative recordings. The tumor blood supply and intraoperative blood loss were recorded, and the tumor blood supply was recorded as abundant or poor. Tumors were classified according to whether the chordoma was with or without septum.

Histopathological analysis. All of the pathological sections were observed by at least two experienced pathological experts who confirmed the diagnosis of chordoma. Chordomas were classified into three types (conventional, chondroid and dedifferentiated) according to the International Agency for Research on Cancer (35). Although no dedifferentiated type was found in this group, a rapid growth subgroup was distinguished from a conventional chordoma according to previous reports (36-38) and previous findings by the authors (39). The chordomas were classified as rapid growth if it met one of the following criteria: i) Necrosis and hemorrhage were present; ii) $\geq 3$ mitotic figures were counted in 10 high-power fields, and iii) Ki-67 $\geq 6 \%$ was identified when available. Therefore, chordomas were classified into three pathological types in the present study: Conventional, chondroid and rapid growth.

MR imaging analysis. Preoperative MR imaging was performed at the Medical Imaging Department of Beijing Tiantan Hospital. All of the images were uploaded and analyzed in the Picture Archiving and Communication System. First, the quality of the MR images were evaluated to ensure the tumor location was sufficiently clear to make a diagnosis, and there was no interference in the measurement of signal intensity (no substantial artifacts or $<10 \%$ artifacts). 
The maximum diameters in the coronal, axial and sagittal planes were measured (D1, D2, and D3, respectively), and the final diameter was recorded as the largest of these three diameters. The lobulation of the tumor was recorded as either with or without lobulation. The extent of resection was determined by the combination of the surgeons' descriptions and analyses of postoperative MR images. Gross total resection (GTR) was defined as a total resection of the visible tumor; if the afflicted bone was removed to expose normal bone tissue, and no tumor was observed in postoperative MR images. Near total resection (NTR) was defined as total resection of the visible tumor and if $>90 \%$ of the tumor was removed in postoperative MR images. In subtotal resection (STR), 70-90\% of the tumor was removed in the postoperative MR images. In partial resection (PR) and biopsy, $<70 \%$ of the tumor was removed. In order to facilitate comparisons, the GTR and NTR groups were combined as marginal resection ( $\geq 90 \%)$, and the STR, PR and biopsy groups were combined as non-marginal resection $(<90 \%)$.

Statistical analysis. Statistical analyses were performed using SPSS software (version 20.0; IBM Corp., Armonk, NY, US). The independence of alleles (Hardy-Weinberg equilibrium) was calculated by chi-square test. The genotype frequencies and allelic frequencies at the two SNPs in LGALS3 were compared between patients with SBC and healthy controls by $\chi^{2}$ test and binary logistic regression analysis. Odds ratios with 95\% confidence intervals (CIs) were also calculated.

For patients with SBC, a descriptive analysis was performed for the continuous and categorical variables. One-way analysis of variance was implemented to analyze the distribution of continuous variables between different SNP genotype groups. A $\chi^{2}$ test was performed to analyze the distribution of categorical variables between different SNP genotype groups. A $\chi^{2}$ test was performed to analyze the distribution of categorical variables between different SNP genotype groups.

The Kaplan-Meier (K-M) test was applied to illustrate the risks of survival and progression between different SNP genotype groups. A cox regression model was used to analyze the survival and progression data if significant differences were found in the K-M analysis. In the cox regression models, each factor was first entered into the regression model for a univariate analysis, and then a multivariate analysis was carried out with the inclusion criteria of 0.1. Patients lost to follow-up were not included in the regression analyses. $\mathrm{P}<0.05$ was considered to indicate statistical significance.

\section{Results}

Identification of SNPs in the galectin-3 gene. The sequence data for LGALS3 +191 C>A (SNP rs4644) and +292 A>C (SNP rs4652) were obtained for all study subjects. The genotype and allele frequencies were in Hardy-Weinberg equilibrium in the healthy control group (Table I). The genotypic and allelic distribution at LGALS3 +191 C>A and +292 A>C in the patient and control groups are listed in Table II.

Analysis of two LGALS3 SNP genotypes between two groups. There were no significant differences observed in the distribution of genotypes $[\mathrm{P}=0.662,95 \%$ confidence interval $(\mathrm{CI})$ :
Table I. Hardy-Weinberg equilibrium of LGALS3 +191 C>A (rs4644) and $+292 \mathrm{~A}>\mathrm{C}(\mathrm{rs} 4652)$.

A, rs4644

\begin{tabular}{lcccc}
\hline Groups & C allele & A allele & $\chi^{2}$ & P-value \\
\hline Chordoma & 0.833 & 0.167 & 0.480 & 0.488 \\
Control & 0.856 & 0.144 & 2.660 & 0.103 \\
\hline
\end{tabular}

B, rs4652

\begin{tabular}{lcccc}
\hline Groups & C allele & A allele & $\chi^{2}$ & P-value \\
\hline Chordoma & 0.208 & 0.792 & 0.644 & 0.422 \\
Control & 0.356 & 0.644 & 1.997 & 0.158
\end{tabular}

LGALS3, galectin 3 .

Table II. Genotype distribution at LGALS3 +191 A>C (rs4644) and $+292 \mathrm{~A}>\mathrm{C}$ (rs4652) in the skull base chordoma and control groups.

A, rs4644

Genotype distribution

\begin{tabular}{lccc}
\cline { 2 - 4 } Groups & CC & AC & AA \\
\hline Chordoma & 34 & 12 & 2 \\
Control & 50 & 13 & 3 \\
\hline
\end{tabular}

B, rs 4652

Genotype distribution

\begin{tabular}{lrrr}
\cline { 2 - 4 } Groups & CC & AC & AA \\
\hline Chordoma & 3 & 14 & 31 \\
Control & 11 & 25 & 30 \\
\hline
\end{tabular}

$0.592-2.279]$ and allele frequencies $(\mathrm{P}=0.638)$ at $\mathrm{LGALS} 3+191$ $\mathrm{C}>\mathrm{A}$ between the SBC group and the control group (Fig. 1A).

Significant difference was observed between the allelic distributions at LGALS3+292 A $>$ C between the SBC group and the control group $(\mathrm{P}=0.016$; Fig. $1 \mathrm{~B})$, and allele $\mathrm{A}$ was associated with the occurrence of SBC. The distribution of the genotypes at LGALS3+292 A>C were not different between the patients with $\mathrm{SBC}$ and control groups in the additive model (CC vs. AC vs. AA, $\mathrm{P}=0.083$; Fig. 1C) but were different in the recessive model $(\mathrm{CC}+\mathrm{AC}$ vs. $\mathrm{AA}, \mathrm{P}=0.043$; Fig. 1D).

Analysis of two LGALS3 SNP loci in patients with SBC. Of the patients included in the present study, the follow-up time ranged from 2 to 116 months (median, 37 months). A total of 2 patients succumbed to disease during in-patient care following the 
Table III. Continuous variables for patients with skull base chordoma.

\begin{tabular}{lrrrrr}
\hline Parameters & Minimum value & Maximum value & Mean & Median & Standard deviation \\
\hline Age, years & 11 & 62 & 37.830 & 40.000 & 12.795 \\
Diameter (mm) & 18 & 81 & 44.900 & 44.500 & 13.515 \\
Blood loss (ml) & 100 & 4,000 & 920.830 & 600.000 & 897.504 \\
Before time (months) $^{\text {a }}$ & 1 & 96 & 15.540 & 10.500 & 20.157 \\
\hline
\end{tabular}

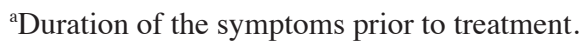

Table IV. Categorical variables for patients with skull base chordoma.

\begin{tabular}{|c|c|c|c|c|c|c|}
\hline Parameters & No. of patients & $\begin{array}{l}\text { Mortality during } \\
\text { inpatient care }\end{array}$ & $\begin{array}{l}\text { Survival } \\
\text { Survived }\end{array}$ & $\begin{array}{c}\text { Progression } \\
\text { Succumbed to disease }\end{array}$ & $\mathrm{N}$ & $\mathrm{Y}$ \\
\hline
\end{tabular}

Sex

Female

23

Male

23

Treatment history

Y

N

Lobulation

$\mathrm{Y}$

$\mathrm{N}$

Septa

Y

$\mathrm{N}$

Blood supply

Abundant

Poor

20

Stage

Subdural

Epidural

Resection grade

$$
>90 \%
$$

$<90 \%$

Histopathology

Conventional

Rapid growth

Chondroid

rs4644

$\mathrm{CC}$

$\mathrm{AC}$

12

AA

rs4652

$\mathrm{CC}$

$\mathrm{AC}$

3

AA

Total

Y, yes; N, no.

2

\section{2}

31

46

\section{7}

5

$\begin{array}{ll}6 & 17\end{array}$

$10 \quad 13$

7

$\begin{array}{rrr}8 & 2 & 13 \\ 4 & 14 & 17\end{array}$

9

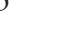

5

9

9

15

2

2

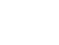

17

17
6

6

11

22

11

2
0

0

\section{0}

2

0

2

\section{9}

3

$9 \quad 19$

$7 \quad 11$

$\begin{array}{rrr}8 & 14 & 19 \\ 4 & 2 & 11\end{array}$

$\begin{array}{rrr}7 & 12 & 14 \\ 5 & 4 & 16\end{array}$

$\begin{array}{rrr}2 & 5 & 9 \\ 10 & 11 & 21\end{array}$

$\begin{array}{rrr}7 & 13 & 18 \\ 5 & 3 & 12\end{array}$

$\begin{array}{rrr}5 & 7 & 15 \\ 3 & 3 & 6 \\ 4 & 6 & 9 \\ & & \\ 10 & 10 & 22 \\ 1 & 6 & 6 \\ 1 & 0 & 2\end{array}$

\section{9}

(

9

1

4



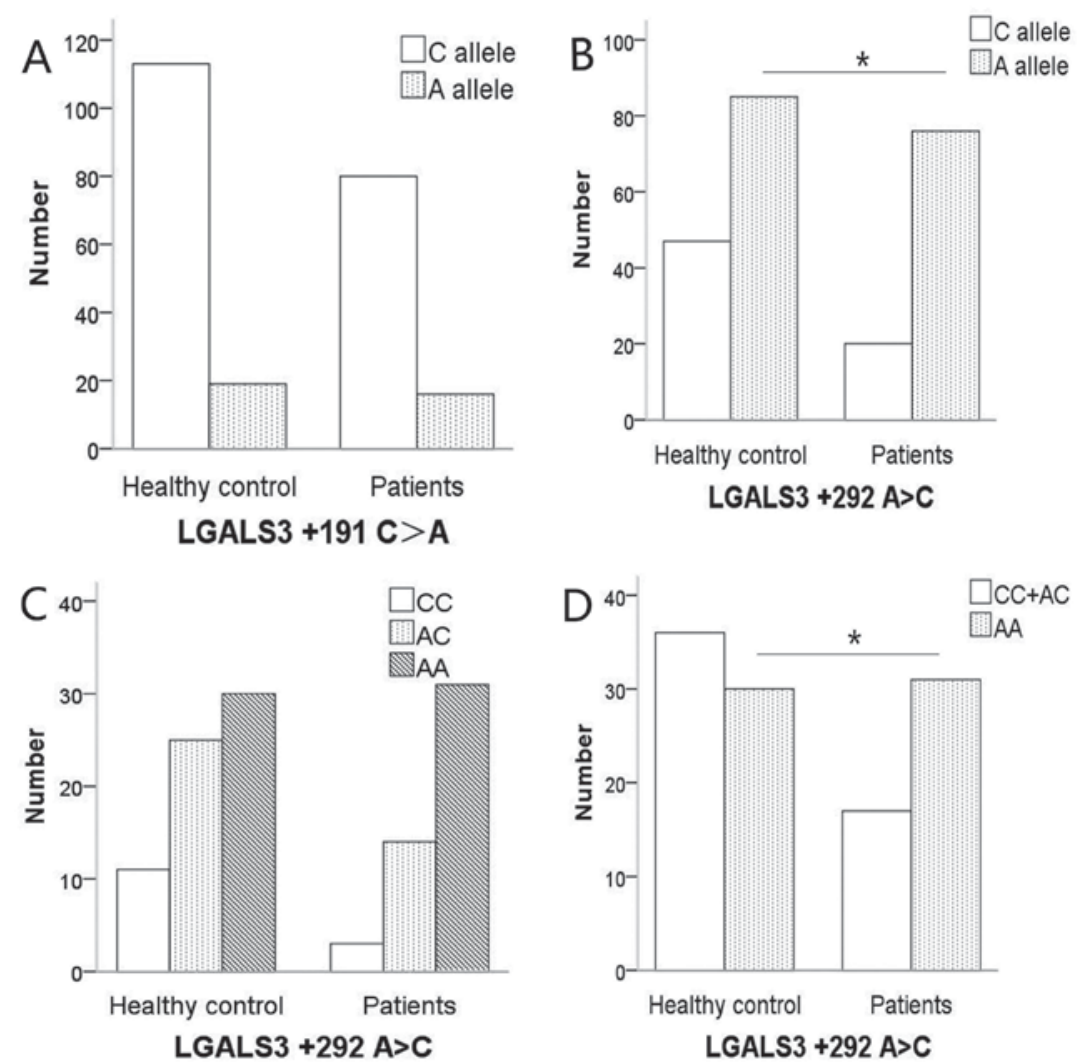

Figure 1. Bar plot illustrating the distribution of genotypes and alleles at LGALS3 $+191 \mathrm{C}>\mathrm{A}$ and $+292 \mathrm{~A}>\mathrm{C}$ in healthy controls and patients. (A) There were no significant differences in the distribution of alleles at $+191 \mathrm{C}>\mathrm{A}$ between healthy controls and patients $\left(\chi^{2}\right.$ test, $\left.\mathrm{P}=0.638\right)$. (B) The frequency of allele $\mathrm{A}$ at +292 $\mathrm{A}>\mathrm{C}$ in patients with $\mathrm{SBC}$ was higher $\left(\chi^{2}\right.$ test, $\left.\mathrm{P}=0.016\right)$ compared with the healthy controls. (C) The distributions of the genotypes at $+292 \mathrm{~A}>\mathrm{C}$ in the two groups. The distribution of the genotypes at LGALS3 $+292 \mathrm{~A}>\mathrm{C}$ was not different in the additive model $\left(\chi^{2}\right.$ test, $\left.\mathrm{P}=0.083\right)$. (D) There was a higher frequency of AA genotypes in patients compared with the healthy controls $\left(\chi^{2}\right.$ test, $\left.\mathrm{P}=0.043\right) .{ }^{*} \mathrm{P}<0.05$ healthy controls vs patients.

A

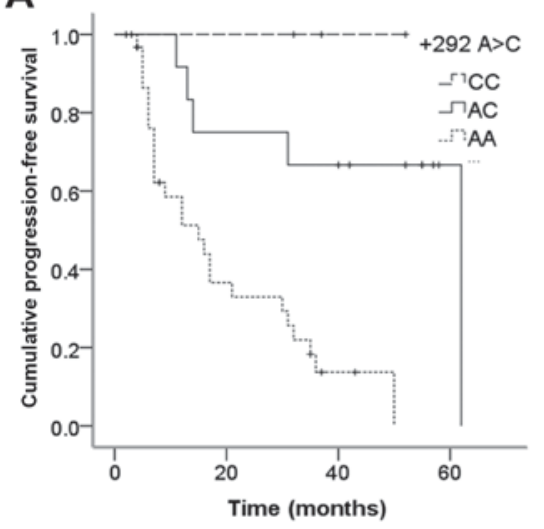

C

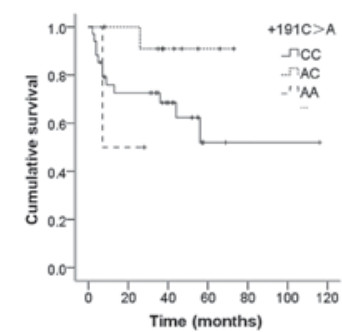

B

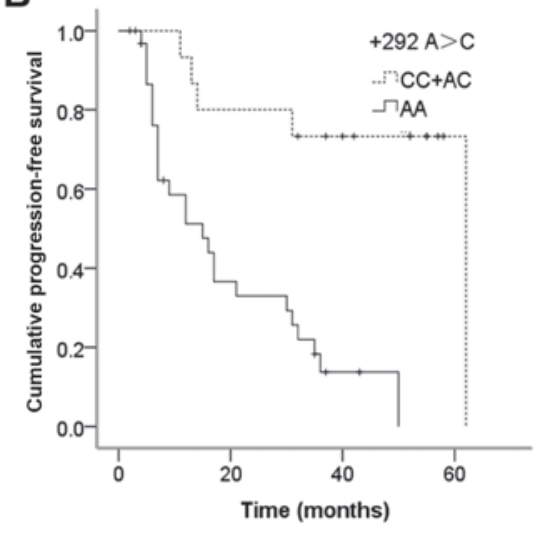

E

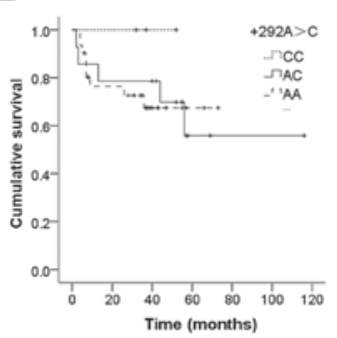

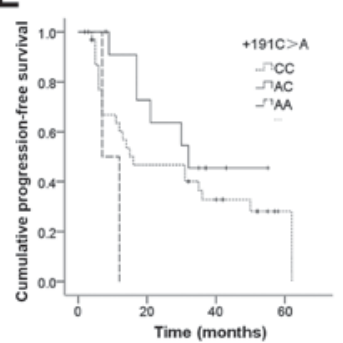

Figure 2. Kaplan-Meier analysis of cumulative survival and PFS for different genotypes of LGALS3. (A) The cumulative PFS was different for the three genotype groups at $+292 \mathrm{~A}>\mathrm{C}(\mathrm{CC}+\mathrm{AC}, \mathrm{P}=0.282$; $\mathrm{CC}+\mathrm{AA}, \mathrm{P}=0.013$; AC+AA, $\mathrm{P}=0.001)$. (B) At $+292 \mathrm{~A}>\mathrm{C}$, patients with CC+AC genotypes had longer cumulative PFS compared with patients with the AA genotype $(\mathrm{P}<0.001)$. The cumulative overall survival for different genotypes at $(\mathrm{C})+191 \mathrm{C}>\mathrm{A}$ and $(\mathrm{D})+292 \mathrm{~A}>\mathrm{C}$ were not statistically different $(\mathrm{P}>0.05)$. (E) There were no differences in cumulative in PFS between the three different genotypes at $+191 \mathrm{C}>\mathrm{A}(\mathrm{P}>0.05)$. LGALS3, galectin 3; PFS, progression-free survival. 
Table V. Distribution of variables in different genotypes of LGALS3 + $191 \mathrm{C}>\mathrm{A}$ (rs4644) and +292 A>C (rs4652) in patients with skull base chordoma.

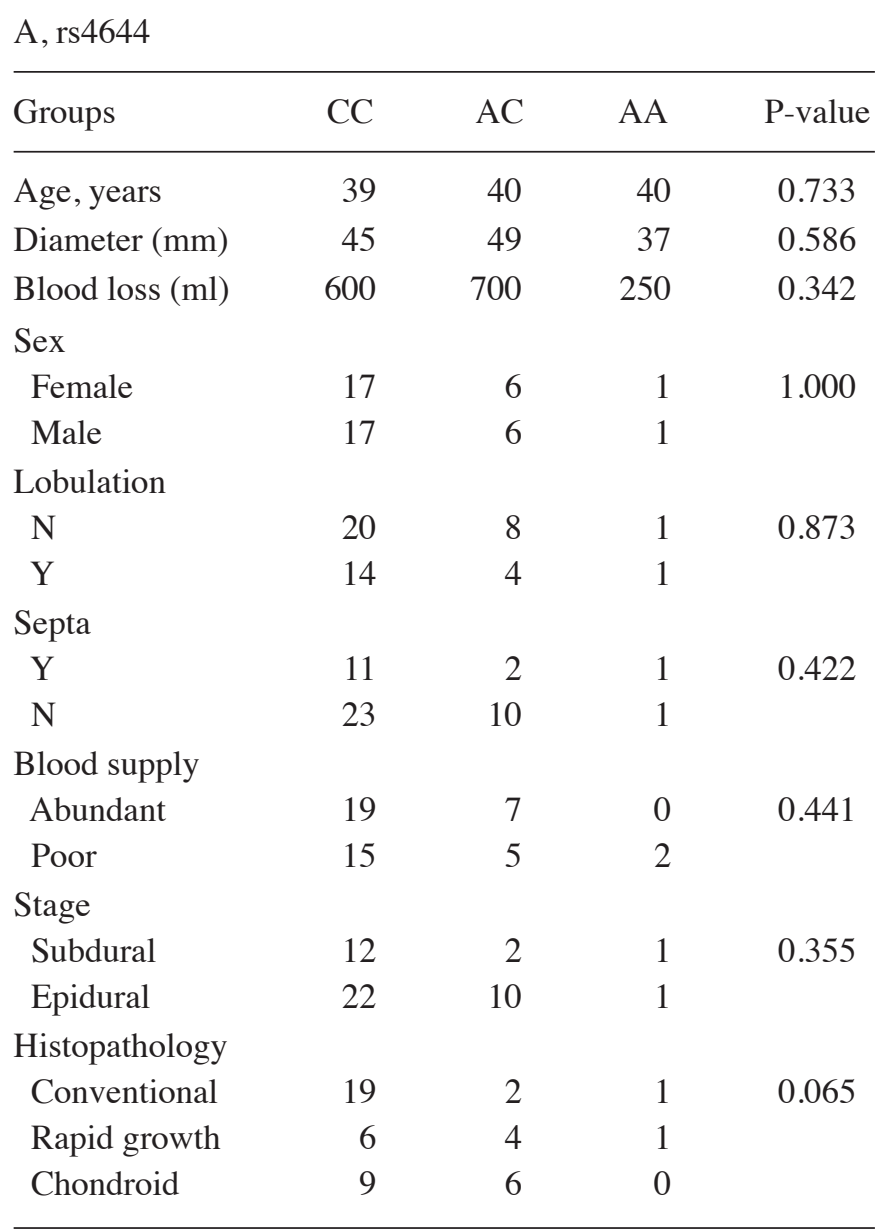

B, rs 4652

\begin{tabular}{|c|c|c|c|c|}
\hline Groups & $\mathrm{CC}$ & $\mathrm{AC}$ & AA & P-value \\
\hline Age, years & 40 & 39 & 40 & 0.670 \\
\hline Diameter (mm) & 32 & 43 & 50 & 0.123 \\
\hline Blood loss (ml) & 600 & 600 & 600 & 0.391 \\
\hline \multicolumn{5}{|l|}{ Sex } \\
\hline Female & 1 & 5 & 18 & \multirow[t]{2}{*}{0.393} \\
\hline Male & 2 & 9 & 13 & \\
\hline \multicolumn{5}{|l|}{ Lobulation } \\
\hline $\mathrm{N}$ & 2 & 5 & 12 & \multirow[t]{2}{*}{0.707} \\
\hline Y & 1 & 9 & 19 & \\
\hline \multicolumn{5}{|l|}{ Septa } \\
\hline $\mathrm{Y}$ & 1 & 5 & 8 & \multirow[t]{2}{*}{0.774} \\
\hline $\mathrm{N}$ & 2 & 9 & 23 & \\
\hline \multicolumn{5}{|l|}{ Blood supply } \\
\hline Abundant & 2 & 7 & 17 & \multirow[t]{2}{*}{1.000} \\
\hline Poor & 1 & 7 & 14 & \\
\hline \multicolumn{5}{|l|}{ Stage } \\
\hline Subdural & 2 & 6 & 7 & \multirow[t]{2}{*}{0.129} \\
\hline Epidural & 1 & 8 & 24 & \\
\hline \multicolumn{5}{|l|}{ Histopathology } \\
\hline Conventional & 1 & 9 & 12 & 0.365 \\
\hline
\end{tabular}

Table V. Continued.

B, rs4652

\begin{tabular}{lllrl}
\hline Groups & CC & AC & AA & P-value \\
\hline Rapid growth & 0 & 2 & 9 & \\
Chondroid & 2 & 3 & 10 & \\
\hline Y, yes; N, no; LGALS3, galectin 3. & & & \\
\hline
\end{tabular}

operation. The regression analyses were performed with the remaining 46 patients. A total of 12 patients succumbed to disease during the study period, and tumor progression was present in 30 patients. The overall survival rate and PFS rate were 73 and $35 \%$ at 3 years and 60 and $30 \%$ at 5 years, respectively. The detailed data for the continuous and categorical variables are presented in Tables III and IV. Only 2 patients experienced postoperative radiotherapy, so this variable was not included in the present study.

The analysis of the SBC characteristics between patients with different genotypes in two LGALS3 SNPs was conducted. There were no differences in age, sex, tumor diameter, intraoperative blood loss, tumor septa, tumor lobulation, tumor blood supply and histopathological type between different genotype groups (Table V).

In the K-M analysis, there were no significant differences in the overall survival and progression analysis between the different genotypes at LGALS3+191 C $>A(P=0.168$ and $\mathrm{P}=0.120$ ), and no significant difference in overall survival was observed between the genotypes at LGALS3+292 A>C $(\mathrm{P}=0.595)$. However, when the dominant model was employed for K-M analysis of for tumor progression between the different genotypes at LGALS3+292 A>C, the PFS time of the CC+AC genotype group was longer compared with the AA genotype group ( $\mathrm{P}<0.0001$; Fig. 2).

In the univariate analysis of tumor progression, the dominant model of LGALS3 SNP genotype at +292 A>C, diameter, time prior to in-patient care, treatment history, tumor septa, tumor blood supply and resection grade were potential significant factors (Fig. 3). After including these factors in the multivariate analysis, the LGALS3 SNP genotype at +292 A $>$ C and treatment history were independent factors for tumor progression. Furthermore, the risk of progression was higher in the AA genotype group compared with the $\mathrm{CC}+\mathrm{AC}$ genotype group (hazard ratio, 7.219, 95\% $\mathrm{CI}, 2.347-22.204, \mathrm{P}=0.001$, Fig. 3)

\section{Discussion}

In the present study, the genotypes LGALS3 +191 C $>\mathrm{A}$ and +292 A>C were sequenced in 48 patients with SBC and 66 healthy controls. It was indicated that the allele A and genotype AA at LGALS3 +292 A>C were associated with the occurrence of SBC. In addition, the genotype AA was associated with larger tumor and shorter PFS.

Galectin-3 participates in many biological processes, including tumor pathogenesis and proliferation (40). Numerous studies have demonstrated that the levels of levels 


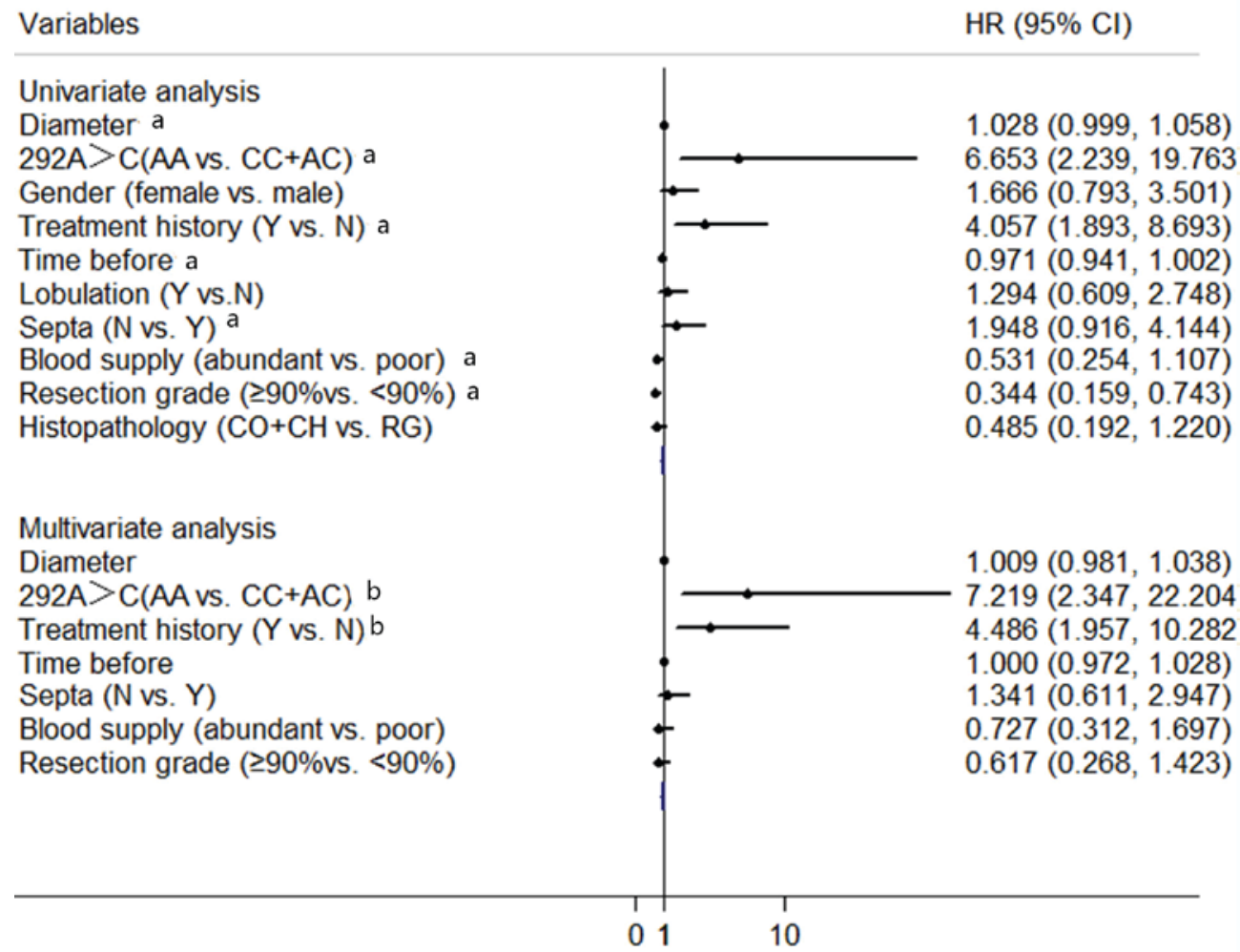

Figure 3. Univariate and Multivariate Cox regression model for tumor progression risk. The black dots indicate the hazard ratio, and horizontal lines represent 95\% CIs. Y, yes; N, no; HR, hazard ratio; CI, confidence interval; $\mathrm{CO}$, conventional; $\mathrm{RG}$, rapid growth; $\mathrm{CH}$, chondroid. ${ }^{\mathrm{a}} \mathrm{P}<0.1 ;{ }^{\mathrm{b}} \mathrm{P}<0.05$.

galectin-3 were higher in chordoma compared with chondrosarcoma (29,30). Shen et al (28) and Wang et al (39) also reported that galectin-3 was highly expressed in chordoma. Shen et al (28) also noted that galectin-3 was not expressed in the normal notochord remnant tissues surrounding the chordoma. Gotz et al (31) demonstrated that the level of galectin-3 was higher in chordoma tissues compared with fetal notochord tissues and adult nucleus pulpous cells. It was known that chordoma arises from the remnants of human notochord tissue, suggesting that galectin-3 may have an important role in the pathogenesis and physiological processes of SBC.

Although several galectin-3 SNP loci have been reported, no report has been published on the association between the presence of galectin-3 SNP loci and the risk of SBC. Meyer et al (41) reported an association between rs4644 (+191 C>A) with LGALS3 and demonstrated that the functional germline mutation Pro64His at this position was associated with a decreased risk of prostate cancer. However, in the present study, no significant differences in the frequency of C $>$ A mutations at LGALS3 +191 were observed between the SBC group and the control group, indicating that variations at this position is not associated with SBC.

Hu et al (34) reported a higher risk of rheumatoid arthritis in members of the Taiwanese population carrying allele $\mathrm{C}$ at LGALS3 +292 A>C with a relatively low concentration of serum galectin-3 protein. Hu et al (34) concluded that the genotype at LGALS3 +292 was likely to affect the secretion of galectin-3 protein, and therefore affect its function in the body. In the present study, it was observed that people carrying the AA genotype and the allele A at LGAS3+292
$\mathrm{A}>\mathrm{C}$ had a higher risk of SBC compared with patients with $\mathrm{CC}$ and $\mathrm{CA}$. Therefore, it was concluded that the variation at this position played a role in the pathological process that associated with SBC by affecting the level of galectin-3 secreted in the body.

Chen et al (32) found that the presence of the AA genotype and allele $\mathrm{A}$ at LGALS3+292 A $>\mathrm{C}$ increased the risk for glioma. Among glioma patients, patients with high-grade glioma and short survival were reported to have higher percentage of the AA genotype compared with the $\mathrm{CC}$ or $\mathrm{AC}$ genotype. There are three pathological types of chordoma: Conventional chordoma (49 cases in the present study), chondroid chordoma (2 cases) and dedifferentiated chordoma (1 case). Due to the limited number of chondroid chordoma and dedifferentiated chordoma and the lack of clinical data, no further analysis was performed in the present study.

A number of previous studies reported that galectin-3 has an important role in tumor metastasis and anti-apoptosis (42-45). Therefore, an analysis of the genotypes of the two SNP loci was undertaken together with clinical features, survival and progression analysis to clarify if different genotypes of galectin-3 affect the clinical features and prognosis of patients with SBC. The results in the present study suggested that the genotypes do not affect the overall survival of patients with SBC. However, it was indicated that the +292 A>C genotype significantly affects PFS, while $+191 \mathrm{C}>\mathrm{A}$ did not. Considering the association between the $+292 \mathrm{~A}>\mathrm{C}$ genotype and the occurrence of SBC as well as the function of galectin-3 mentioned previously, it was concluded that that the $+292 \mathrm{~A}>\mathrm{C}$ genotype was associated with progression of SBC. 
The present study analyzed the genotypes of LGALS3 in SBC. However, there are a number of limitations. First, as the incidence of SBC is extremely low, the number of cases included in the present study is relatively small. Consequently, the conclusions need to be confirmed using a larger number of cases. Secondly, the length of the follow-up time was not sufficient, therefore these patients will continue to be followed up and a more comprehensive analysis will be carried out. Finally, all subjects in the present study were Chinese, so whether the results are applicable to other ethnic groups is not yet known.

In summary, among the population in China, the presence of allele A and AA genotype at LGALS3 +292 A>C were found to be associated with a higher risk of $\mathrm{SBC}$, and $\mathrm{AA}$ genotype at $+292 \mathrm{~A}>\mathrm{C}$ were associated with larger tumors and a shorter PFS. The present study provides a basis for further studies on galectin-3 in patients with SBC at the genetic level.

\section{Acknowledgements}

Not applicable.

\section{Funding}

The present study was supported in part by the National Natural Science Foundation of China (grant nos. 81472370 and 81541146), the Natural Science Foundation of Beijing Municipality, China (grant no. 7142052) and the Beijing Municipal Science and Technology Commission (grant no. Z131107002213179).

\section{Availability of data and materials}

The datasets used and/or analyzed during the current study are available from the corresponding author on reasonable request.

\section{Authors' contributions}

KT, LW, KW, JM, DL, YY, GJ and JZ analyzed and interpreted the patient data and conducted the experiments. KT, LW, LZ, ZW and JZ set up the database and analyzed the data. KT, LZ, $\mathrm{ZW}$ and $\mathrm{JZ}$ contributed to writing the manuscript. All authors read and approved the final manuscript.

\section{Ethics approval and consent to participate}

The present study is in accordance with the Code of Ethics of the World Medical Association (Declaration of Helsinki) for experiments involving humans and was approved by the ethics committees of Beijing Tiantan Hospital (Beijing, China) and the Capital Medical University (Beijing, China). All patients provided written informed consent forms prior to the start of the study.

\section{Consent for publication}

All patients provided written informed consent prior to the study. Identifying information was not included in this article.

\section{Competing interests}

The authors declare that they have no competing interest.

\section{References}

1. Chambers KJ, Lin DT, Meier J, Remenschneider A, Herr M and Gray ST: Incidence and survival patterns of cranial chordoma in the United States. Laryngoscope 124: 1097-1102, 2014.

2. Smoll NR, Gautschi OP, Radovanovic I, Schaller K and Weber DC: Incidence and relative survival of chordomas: The standardized mortality ratio and the impact of chordomas on a population. Cancer 119: 2029-2037, 2013.

3. McMaster ML, Goldstein AM, Bromley CM, Ishibe N and Parry DM: Chordoma: Incidence and survival patterns in the United States, 1973-1995. Cancer Causes Control 12: 1-11, 2001.

4. Salisbury JR: The pathology of the human notochord. J Pathol 171: 253-255, 1993.

5. Ho KL: Ecchordosis physaliphora and chordoma: A comparative ultrastructural study. Clin Neuropathol 4: 77-86, 1985.

6. Ridenour RR III, Ahrens WA, Folpe AL and Miller DV: Clinical and histopathologic features of chordomas in children and young adults. Pediatr Dev Pathol 13: 9-17, 2010.

7. Jahangiri A, Chin AT, Wagner JR, Kunwar S, Ames C, Chou D, Barani I, Parsa AT, McDermott MW, Benet A, et al: Factors predicting recurrence after resection of clival chordoma using variable surgical approaches and radiation modalities. Neurosurgery 76: 179-186, 2015.

8. Bohman LE, Koch M, Bailey RL, Alonso-Basanta M and Lee JY: Skull base chordoma and chondrosarcoma: influence of clinical and demographic factors on prognosis: A SEER analysis. World Neurosurg 82: 806-814, 2014

9. Tzortzidis F, Elahi F, Wright D, Natarajan SK and Sekhar LN: Patient outcome at long-term follow-up after aggressive microsurgical resection of cranial base chordomas. Neurosurgery 59: 230-237, 2006.

10. Williams BJ, Raper DM and Godbout E, Bourne TD, Prevedello DM, Kassam AB and Park DM: Diagnosis and treatment of chordoma. J Natl Compr Canc Netw 11: 726-731, 2013.

11. Jian BJ, Bloch OG and Yang I, Han SJ, Aranda D, Tihan T and Parsa AT: Adjuvant radiation therapy and chondroid chordoma subtype are associated with a lower tumor recurrence rate of cranial chordoma. J Neurooncol 98: 101-108, 2010.

12. Amendola BE, Amendola MA, Oliver E and McClatchey KD: Chordoma: Role of radiation therapy. Radiology 158: 839-843, 1986.

13. Wu Z, Zhang J, Zhang L, Jia G, Tang J, Wang L and Wang Z: Prognostic factors for long-term outcome of patients with surgical resection of skull base chordomas-106 cases review in one institution. Neurosurg Rev 33: 451-456, 2010.

14. Raz A,Meromsky L,ZvibelI and Lotan R: Transformation-related changes in the expression of endogenous cell lectins. Int J Cancer 39: 353-360, 1987.

15. Cerra RF, Gitt MA and Barondes SH: Three soluble rat beta-galactoside-binding lectins. J Biol Chem 260: 10474-10477, 1985.

16. Roff CF and Wang JL: Endogenous lectins from cultured cells. Isolation and characterization of carbohydrate-binding proteins from 3T3 fibroblasts. J Biol Chem 258: 10657-10663, 1983.

17. Ho MK and Springer TA: Mac-2, a novel 32,000 Mr mouse macrophage subpopulation-specific antigen defined by monoclonal antibodies. J Immunol 128: 1221-1228, 1982.

18. Barondes SH, Castronovo V, Cooper DN, Cummings RD, Drickamer K, Feizi T, Gitt MA, Hirabayashi J, Hughes C, Kasai K, et al: Galectins: A family of animal beta-galactoside-binding lectins. Cell 76: 597-598, 1994.

19. Kadrofske MM, Openo KP and Wang JL: The human LGALS3 (galectin-3) gene: Determination of the gene structure and functional characterization of the promoter. Arch Biochem Biophys 349: 7-20, 1998.

20. Raimond J, Zimonjic DB, Mignon C, Mattei M, Popescu NC, Monsigny $\mathrm{M}$ and Legrand A: Mapping of the galectin-3 gene (LGALS3) to human chromosome 14 at region 14q21-22. Mamm Genome 8: 706-707, 1997.

21. Giordano M, Croci DO and Rabinovich GA: Galectins in hematological malignancies. Curr Opin Hematol 20: 327-335, 2013.

22. van den Brûle F, Califice S and Castronovo V: Expression of galectins in cancer: A critical review. Glycoconj J 19: 537-542, 2004.

23. Binh NH, Satoh K, Kobayashi K, Takamatsu M, Hatano Y, Hirata A, Tomita H, Kuno T and Hara A: Galectin-3 in preneoplastic lesions of glioma. J Neurooncol 111: 123-132, 2013.

24. Dawson H, André S, Karamitopoulou E, Zlobec I and Gabius HJ: The growing galectin network in colon cancer and clinical relevance of cytoplasmic galectin-3 reactivity. Anticancer Res 33: 3053-3059, 2013. 
25. Eliaz I: The role of galectin-3 as a marker of cancer and inflammation in a stage IV ovarian cancer patient with underlying pro-inflammatory comorbidities. Case Rep Oncol 6: 343-349, 2013.

26. Wang Y, Balan V, Gao X, Reddy PG, Kho D, Tait L and Raz A: The significance of galectin-3 as a new basal cell marker in prostate cancer. Cell Death Dis 4: e753, 2013.

27. Xue G, Liu J, Huang J, Zhang J, Zhang W, Wu J and Shang X: Detection of galectin-3 in both serum and tissue for early diag nosis of thyroid carcinoma. Nan Fang Yi Ke Da Xue Xue Bao 33 1027-1030, 2013 (In Chinese).

28. Shen J, Li CD, Yang HL, Lu J, Zou TM, Wang DL and Deng M: Classic chordoma coexisting with benign notochordal cell rest demonstrating different immunohistological expression patterns of brachyury and galectin-3. J Clin Neurosci 18: 96-99, 2011

29. Cho HY, Lee M, Takei H, Dancer J, Ro JY and Zhai QJ: Immunohistochemical comparison of chordoma with chondrosarcoma, myxopapillary ependymoma, and chordoid meningioma. Appl Immunohistochem Mol Morphol 17: 131-138, 2009.

30. Juliao SF, Rand N and Schwartz HS: Galectin-3: A biologic marker and diagnostic aid for chordoma. Clin Orthop Relat Res: 70-75, 2002.

31. Götz W, Kasper M, Miosge N and Hughes RC: Detection and distribution of the carbohydrate binding protein galectin-3 in human notochord, intervertebral disc and chordoma. Differentiation 62: 149-157, 1997.

32. Chen HJ, Zheng ZC, Yuan BQ, Liu Z, Jing J and Wang SS: The effect of galectin-3 genetic variants on the susceptibility and prognosis of gliomas in a Chinese population. Neurosci Lett 518 : $1-4,2012$.

33. Trompet S, Jukema W, Mooijaart SP, Ford I, Stott DJ, Westendorp RG and de Craen AJ: Genetic variation in galectin-3 gene associates with cognitive function at old age. Neurobiol Aging 33: 2232.e1-2232.e9, 2012.

34. Hu CY, Chang SK, Wu CS, Tsai WI and Hsu PN: Galectin-3 gene (LGALS3) +292 C allele is a genetic predisposition factor for rheumatoid arthritis in Taiwan. Clin Rheumatol 30: 1227-1233, 2011.

35. Flanagan AM and Yamaguchi T: Chordoma. In: Fletcher CDM, Bridge JA, Pancras CW, Mertens F (eds). World Health Organization (WHO) classification of tumors of soft tissue and bone. Pathology and Genetics. IARC Press, Lyon, pp328-329, 2013.
36. Tauziéde-Espariat A, Bresson D, Polivka M, Bouazza S, Labrousse F, Aronica E, Pretet JL, Projetti F, Herman P, Salle H, et al: Prognostic and therapeutic markers in chordomas: A study of 287 tumors. J Neuropathol Exp Neurol 75: 111-120, 2016.

37. Holton JL, Steel T, Luxsuwong M, Crockard HA and Revesz T: Skull base chordomas: Correlation of tumour doubling time with age, mitosis and Ki67 proliferation index. Neuropathol Appl Neurobiol 26: 497-503, 2000.

38. Forsyth PA, Cascino TL, Shaw EG, Scheithauer BW, O'Fallon JR, Dozier JC and Piepgras DG: Intracranial chordomas: A clinicopathological and prognostic study of 51 cases. J Neurosurg 78: 741-747, 1993

39. Wang L, Wu Z, Tian K, Li G and Zhang J: Clinical and pathological features of intradural retroclival chordoma. World Neurosurg 82: 791-798, 2014

40. Dumic J, Dabelic S and Flögel M: Galectin-3: An open-ended story. Biochim Biophys Acta 1760: 616-635, 2006.

41. Meyer A, Coinac I, Bogdanova N, Dubrowinskaja N, Turmanov N, Haubold S, Schürmann P, Imkamp F, von Klot C, Merseburger AS, et al: Apoptosis gene polymorphisms and risk of prostate cancer: A hospital-based study of German patients treated with brachytherapy. Urol Oncol 31: 74-81, 2013.

42. Oka N, Nakahara S, Takenaka Y, Fukumori T, Hogan V, Kanayama HO, Yanagawa T and Raz A: Galectin-3 inhibits tumor necrosis factor-related apoptosis-inducing ligand-induced apoptosis by activating Akt in human bladder carcinoma cells. Cancer Res 65: 7546-7553, 2005.

43. Lee YJ, Song YK, Song JJ, Siervo-Sassi RR, Kim HR, Li L, Spitz DR, Lokshin A and Kim JH: Reconstitution of galectin-3 alters glutathione content and potentiates TRAIL-induced cytotoxicity by dephosphorylation of Akt. Exp Cell Res 288: 21-34, 2003.

44. Yang RY, Hsu DK and Liu FT: Expression of galectin-3 modulates T-cell growth and apoptosis. Proc Natl Acad Sci USA 93: 6737-6742, 1996

45. Inohara H, Akahani S, Koths $\mathrm{K}$ and Raz A: Interactions between galectin-3 and Mac-2-binding protein mediate cell-cell adhesion. Cancer Res 56: 4530-4534, 1996. 